\title{
Income and Mental Well-Being: Personality Traits as Moderators
}

\author{
Susanne M. Syrén ${ }^{1}$ (D) Katja Kokko ${ }^{2}$. Lea Pulkkinen ${ }^{3}$ (D) Jaakko Pehkonen ${ }^{1}$ (D) \\ Published online: 23 January 2019 \\ (c) The Author(s) 2019
}

\begin{abstract}
Using data from the participants of the Jyväskylä Longitudinal Study of Personality and Social Development (JYLS) at ages 42 and $50(\mathrm{~N}=326)$, this study provides empirical evidence of the relation between income and mental well-being and of the possible role of personality traits in modifying this relation. The relationships were analyzed using pooled ordinary least squares (OLS; bi- and multivariate settings) and fixed effects estimations (FE; multivariate settings). Positive bivariate associations were found between gross monthly income and the sum score of mental well-being and its separate dimensions (emotional, psychological, and social well-being and the absence of depression) as well as between experienced household finances and the sum score of mental well-being and its separate dimensions (except for social well-being). The multivariate OLS analyses detected positive relationships between gross monthly income and the absence of depression and between experienced household finances and mental well-being, along with one of its dimensions, i.e., emotional well-being. Further, the marginal utility of income appeared to depend on personality traits $(\mathrm{FE})$ : agreeableness and extraversion negatively moderated the gross monthly income-emotional well-being relationship, while openness positively moderated this relationship. In addition to emotional well-being, extraversion negatively moderated the relationship between gross monthly income and general mental well-being, and neuroticism negatively moderated the association between gross monthly income and social well-being.
\end{abstract}

Keywords Mental well-being $\cdot$ Emotional well-being $\cdot$ Psychological well-being $\cdot$ Social well-being $\cdot$ Depression $\cdot$ Income $\cdot$ Big Five personality traits

Susanne M. Syrén

susanne.syren@jyu.fi

1 Jyväskylä University School of Business and Economics, University of Jyväskylä, P.O. Box 35, 40014 Jyväskylä, Finland

2 Gerontology Research Center and Faculty of Sport and Health Sciences, University of Jyväskylä, Jyväskylä, Finland

3 Department of Psychology, University of Jyväskylä, Jyväskylä, Finland 


\section{Introduction}

The relationship between income and well-being has been extensively analyzed over the last four decades. Empirical research has focused on numerous developed and developing countries over various time periods. For example, Stevenson and Wolfers (2008) found a positive correlation between gross domestic product (GDP) and both happiness and life satisfaction in developed and developing countries. Regarding different time periods, a strong positive short-term relationship has been reported between GDP and happiness (Deaton 2008; Stevenson and Wolfers 2008), whereas Easterlin et al. (2010) suggested that there was no long-run relationship between GDP growth and life satisfaction.

The existing economics literature has paid limited attention to defining well-being, typically describing this in terms of happiness or life satisfaction, with these concepts being treated synonymously (e.g., Frey 2008; Veenhoven 1991) or as different notions of wellbeing (e.g., Deaton 2008; Inglehart et al. 2008). In the psychological literature, happiness and life satisfaction constitute components of emotional well-being, also called subjective well-being, together with high positive and low negative affectivity (Diener 1984). Psychological research has also examined psychological well-being, manifested as one's attempt at self-actualization and personal growth (Ryff 1989), and social well-being, indicative of one's resolution in social tasks and encounters (Keyes 1998). Emotional, psychological (Ryff 1989), and social well-being (Keyes 1998) are part of Keyes' (2002, 2005) tripartite model of well-being, which has been empirically corroborated (Gallagher et al. 2009; Keyes 2005; Kokko et al. 2013b; Robitschek and Keyes 2009). Further, using the same data from the Jyväskylä Longitudinal Study of Personality and Social Development (JYLS) as the present study, these well-being indicators have been shown to correlate negatively with ill-being, such as depression, in mid-adulthood (Kokko et al. 2013b). Emotional, psychological, and social well-being, together with the absence of ill-being, capture a latent factor of well-being (Kokko et al. 2013b), referred to as mental well-being (Kokko et al. 2015). Our aim in the present study was to shed further light on the relationship between income and both mental well-being and its various dimensions. Studying the different dimensions of mental well-being is important, because different aspects of well-being differ in what influences them and what they influence (Diener et al. 2017). It is further important for learning about and understanding the income-mental well-being relationship and for designing policies related to, for example, income taxation and welfare benefits.

Based on the JYLS and other empirical research, personality is closely related to wellbeing (e.g., Diener et al. 1999; Steel et al. 2008; Kokko et al. 2013a). Personality traits are further associated with income (e.g., Mueller and Plug 2006; Viinikainen et al. 2010) and with individuals' economic and financial decision-making (Brown and Taylor 2014). Moreover, personality has received increasing attention in research regarding the associations between income and well-being. Theoretically, as individuals have heterogeneous preferences (Sen 1973), particular preference types may extract greater utility from a given income increase (Boyce and Wood 2011). Soto and Luhmann (2012) further argue that effects of life circumstances on subjective well-being may vary depending on personality traits. Therefore, the marginal utility from an income increase on well-being may depend on personality traits. Empirically, Boyce and Wood (2011) showed that an increase in monthly income induced higher levels of life satisfaction for individuals with higher conscientiousness scores than for those with lower scores. Further, Proto and Rustichini (2015) as well as Soto and Luhmann (2012) reported that an increase in income was associated with higher levels of life satisfaction for individuals with high neuroticism scores than for 
those with low scores. Nevertheless, the empirical literature lacks evidence on whether personality moderates the link-i.e., affects well-being reactions arising from changes in income-between income and mental well-being and its dimensions. ${ }^{1}$ In the analysis, the existing economic literature has assumed complete stability of personality traits (Boyce and Wood 2011; Soto and Luhmann 2012; Proto and Rustichini 2015) due to convenience or unavailability of personality measures. We add to the literature by allowing individual variability in the Big Five personality traits.

Our analyses are based on the Finnish age-cohort group drawn from the JYLS (Pulkkinen 2017). ${ }^{2}$ The study aimed to contribute to the literature by exploring: (1) the associations between income and mental well-being, including its dimensions (emotional, psychological, and social well-being and the absence of depression; Keyes 2002, 2005; Kokko et al. 2013b) and (2) the possible role of the Big Five personality traits (agreeableness, extraversion, conscientiousness, openness to new experiences, and neuroticism; Costa and McCrae 1985) in modifying this relation. To answer these questions, we quantified income by using measures of individual income (gross monthly income) and the experienced financial situation of the household (household finances). We employed a longitudinal approach, which allowed us to observe the same individuals and changes in their income, mental well-being, and personality traits between the ages of 42 and 50. This approach also allowed us to control for unobserved time-invariant characteristics and to increase the efficiency of the estimations.

\subsection{The Concept of Mental Well-Being and Its Relation to Income}

Mental well-being is comprised of emotional, psychological, and social well-being, together with the absence of ill-being (Keyes 2005; Kokko et al. 2015). Emotional wellbeing describes how and why individuals experience their lives in a positive way (Diener 1984). Individual income and the household's financial situation have been positively linked to emotional well-being, both theoretically (e.g., Sen 1999) and empirically (e.g., Angeles 2011; Boyce and Wood 2011; Brown and Gray 2016; Headey and Wooden 2004). The components of emotional well-being usually include happiness, life satisfaction, and positive and negative moods (e.g., Diener 1984; Russell and Carroll 1999).

Psychological well-being emphasizes personal growth and living out one's possibilities (Keyes 2006; Ryff 1989; Waterman 1993) and consists of six dimensions: self-acceptance, positive relationships with others, environmental mastery, autonomy, purpose in life, and personal growth (Ryff 1989). The economics literature has shown that debt, particularly unsecured debt, is negatively related to psychological well-being (Brown et al. 2005). Income is further associated with a sense of mastery and control (Lachman and Weaver 1998), and it is positively related to emotional (Kokko et al. 2013a; Ryff and Keyes 1995) and social (Keyes and Waterman 2003; Kokko et al. 2013a) well-being.

Social well-being relates to the surrounding society and describes how an individual evaluates his/her relationship with other people, residential area, and community (Keyes 1998). The components of social well-being are social acceptance, social coherence,

\footnotetext{
1 The moderating role of the Big Five personality traits is studied using fixed effects estimation which utilizes within-individual variation. For example, the estimate of income is identified from changes in withinindividual income. In this paper we refer to this within-individual variation with "changes in income".

2 The JYLS data has been extensively utilized, but the present focus on the combined effects of personality and income on mental well-being has not previously been examined.
} 
social integration, social contribution, and social actualization. Social well-being is further related to the relative income hypothesis, which postulates that higher levels of happiness require higher levels of income relative to a reference group (Clark et al. 2008). The relevant reference group could consist of a circle of acquaintances, neighbors, or the whole world - through globalization (Clark et al. 2008; Deaton 2008). The existing literature has substantiated the relative income hypothesis by using both individual (Ferrer-i-Carbonell 2005) and household income (Brown and Gray 2016; Luttmer 2005).

We measured the absence of ill-being as low depression. According to Zimmerman and Katon (2005), high income may reduce financial distress and provide greater levels of resources for treating depression. Empirical studies have shown that financial strain is associated with symptoms of depression (Zimmerman and Katon 2005), that sudden loss of wealth is associated with feelings of depression (McInerney et al. 2013), and that debt is positively related to anxiety (Drentea 2000).

\subsection{Description and Time Variability of the Big Five Personality Traits}

The Big Five personality traits include agreeableness, extraversion, conscientiousness, neuroticism, and openness to new experiences (Costa and McCrae 1989). According to Costa and McCrae (1989), a highly agreeable individual is trustful, straightforward, altruistic, compliable, modest, and tenderminded. Regarding extraversion, a high score is characterized by warmness, gregariousness, assertiveness, activeness, and excitement seeking. Highly conscientious individuals can be characterized as competent, dutiful, achievement striven, self-disciplined, and deliberate. Conversely, high neuroticism is related, for example, to anxiety, hostility, and vulnerability to stress. Finally, openness to new experiences relates to fantasy, aesthetics, feelings, actions, ideas, and values.

Although psychological studies have shown the absolute (mean level) and relative (correlative) stability of personality traits at the population level over time (e.g., Kokko et al. 2015), there are absolute and relative changes in these traits at the individual level. The JYLS (Pulkkinen 2017, pp. 90, 95) showed that the mean of neuroticism decreased and that of agreeableness increased until age 42 . From age 42 to 50 , the means remained on the same level. There was, however, individual variation within the mean scores. For instance, agreeableness did not increase over time in some individuals or in all sub-groups, although it generally increased. The correlations between ages 42 and 50 varied from 0.70 to 0.80 for all the traits. A stability coefficient of 0.80 indicates that only $64 \%$ of the variance across the two time points was shared and that the rest was explained by true individual variability and measurement error. Since the personality tests measuring the Big Five personality traits are generally highly reliable, part of the variance was explained by true individual variability.

In addition to the present JYLS data, the empirical literature supports the existence of both individual- and mean-level changes throughout the life span. Roberts and Mroczek (2008) illustrated that individuals have unique patterns of development, which are affected by life experiences. In a meta-analysis conducted using longitudinal studies, Roberts et al. (2006b) also showed statistically significant mean-level changes in Big Five personality traits in middle (40-60) and old (>60) age. Personality changes can result from environmental changes in social roles or cultural milieu (Helson et al. 2002a; Scollon and Diener 2006) or from life and work experiences (e.g., Roberts et al. 2003; Roberts et al. 2006a; Mroczek and Spiro 2003; Elkins et al. 2017; Anger et al. 2017; Golsteyn and SchildbergHörisch 2017). 
The question of whether personality changes represent temporary fluctuations or measurement error has also been addressed in the empirical literature through the use of the Reliable Change Index (Roberts et al. 2001) and growth models (e.g., Helson et al. 2002b; Mroczek and Spiro 2003; Small et al. 2003). This literature has established that variability across individuals, both in the direction and rate of personality change, can be demonstrated by the Big Five personality traits (Roberts and Mroczek 2008). Recent literature has further implied that economic models ignoring the personality change may be incorrectly specified (Boyce et al. 2013). All things considered, we believe that it is reasonable to treat personality traits as time-variant and to make statistical inferences based on personality changes. In this study, we examined what happens to the marginal utility of income on mental well-being and its dimensions when within-individual personality-trait changes are taken into account.

\section{Method}

\subsection{Data Collection and the Population of the Study}

The JYLS began in 1968, since which six data collection phases have been conducted (Pulkkinen 2017). The initial sample consisted of 12 randomly selected second-grade school classes in the town of Jyväskylä, Finland. These classes comprised 369 eight-yearold pupils (173 girls and 196 boys), with an initial participation rate of $100 \%$. The participants were mailed a Life Situation Questionnaire (LSQ), inviting them to participate in a semi-structured psychological interview, with self-report inventories and medical examinations using laboratory tests. More information about the data collection can be found in Pulkkinen (2017) reference.

\subsection{Present Sample and the Representativeness}

We utilized JYLS data collected at ages 42 and 50 (in 2001 and 2009, respectively). By ages 42 and 50, six and twelve participants had died, yielding available sample sizes of 363 and 357, respectively. At age $42,77 \%$ of the available sample returned the LSQ, and $71 \%$ participated in the interview. At age 50, the LSQ was returned by $76 \%$ of the available sample, and 64\% took part in the interview. At ages 42 and 50, 163 participants had no missing data regarding any of the studied variables. In the present analysis, we pooled information about these participants, yielding a total of 326 observations.

At ages 42 and 50, the participants were representative of the initial sample in terms of socioemotional behavior at age eight and school achievement at age 14 (Pulkkinen 2017). Furthermore, compared against the statistics provided by Statistics Finland, these participants represented the Finnish age-cohort group born in 1959 with respect to marital status, number of children, and employment. To examine attrition, we compared, at age eight, the present sample $(\mathrm{N}=163)$ with those who were excluded due to missing data $(\mathrm{N}=206)$. Regarding socioemotional behavior in childhood (Pulkkinen et al. 2012), the t-tests for independent groups revealed no statistically significant differences between the groups in terms of behavioral activity $(p=0.61)$. However, the excluded participants scored higher on negative emotionality $(p=0.028)$ and lower on well-controlled behavior $(p=0.046)$ than those who were included. No between-group differences were observed in school 
success $(p=0.28)$ or parental occupational status $(p=0.91)$. We concluded that the present sample represents the initial sample reasonably well.

\subsection{Measures and Variables}

In the LSQ, the participants were asked to rate their gross monthly income (including all taxable income, pensions, and social benefits, but not capital income) using a pre-refined response scale (Pulkkinen and Kokko 2010). At age 42, the scale ranged from 1 to 12 (FIM4000 or less to over FIM32,000) and at age 50 from 1 to 14 (€1000 or less to over $€ 7000)$. For the statistical analyses, we utilized the averages of the income classes, converted Finnish marks into euros, and adjusted for inflation using the Consumer Price Index (Official Statistics of Finland). For the top-coded groups, we utilized the lower bound of the income classes. At age 50, the annual income information from the tax authority registers was available for 158 of our sample of 163 . For these 158 participants, the Spearman correlation between the self-evaluated gross monthly income and the register-based annual income was 0.87 , with a pairwise correlation of $0.83(p<0.01$ in both cases). Such high correlations suggest that the participants accurately evaluated their gross monthly income. In addition to individual income, we evaluated experienced household finances, which implicitly account for factors that may tighten a participant's financial situation, such as liabilities. The participants evaluated their experienced household finances at ages 42 and 50 based on the following question presented in the LSQ: "How do you consider your current personal financial situation or that of the family you have set up?" The scale included $1=$ extremely tight, 2 = fairly tight, 3 = fairly good, and $4=$ extremely good financial situation.

Emotional well-being was measured at ages 42 and 50 using the sum of the standardized scores $^{3}$ of four subcomponents: happiness, life satisfaction, positive mood, and reversed negative mood. Happiness was assessed with the question: "How happy or satisfied have you been at the different stages in your life (Perho and Korhonen 1993)?" The response scale ranged from -3 to +3 (very unhappy or dissatisfied to very happy or satisfied). At age 42 , the most recent time point referred to ages 40-42 years, whereas at age 50, the participants were asked to estimate their current happiness and satisfaction. General life satisfaction was based on seven life domains (for which an average score was calculated): housing, financial situation, choice of occupation, present occupational situation, present intimate relationship or lack thereof, content of leisure time, and present state of friendships (Kokko et al. 2013b), with the response scale ranging from 1 to 4 (very dissatisfied to very satisfied). Positive and negative moods were measured using the Brief Mood Introspection Scale (Feldman 1995; Mayer and Gaschke 1988). Positive mood was calculated as an average score of two items (e.g., "My present mood is satisfied") and negative mood as an average score of five items (e.g., "My present mood is frightened"; Kokkonen 2001; Kokko et al. 2013b). The response scale ranged from 1 to 4 (does not describe my mood at all to describes my mood very well).

Psychological well-being was based on the Scales of Psychological Well-Being (Ryff 1989) at ages 42 and 50, which consisted of 18 items (e.g., "In general, I feel I am in

\footnotetext{
3 The standardization of the scores for general well-being and its dimensions and the personality traits was conducted in Stata as follows: for each observation, the mean of the variable was subtracted from the value of the observation. This difference was then divided by the standard deviation of the variable.
} 
charge of the situation in which I live"). Social well-being was measured using the Scales of Social Well-Being (Keyes 1998) at the same ages, which consisted of 15 items (e.g., "I have something valuable to give the world"). For both psychological and social well-being, the response scale ranged from 1 to 4 (strongly disagree to strongly agree). Depression was assessed at ages 42 and 50 using the Depression Scale of General Behavior Inventory (Depue 1987), which consisted of 16 items (e.g., "Have you become sad, depressed or irritable for several days or more without really understanding why?"). The response scale varied from 1 to 4 (never to very often). Average scores were calculated, and Cronbach's alpha reliability was higher than 0.63 for all the above cases (Kokko et al. 2015). Finally, we constructed mental well-being at ages 42 and 50 by summing the standardized scores for emotional, psychological, and social well-being and reversed depression.

Personality traits were measured at age 33 using the Big Five Personality Inventory (Pulver et al. 1995). This is an authorized adaptation of the NEO Personality Inventory (NEO-PI), which contains 180 items (Costa and McCrae 1985), about one-fourth of which are substitutes for the original American items (Rantanen et al. 2007). A shortened version was formed in order to correspond with the shortened 60-item NEO-Five-Factor Inventory (NEO-FFI; Costa and McCrae 1989). In the Finnish NEO-FFI, which was administered to the participants at ages 42 and 50 (Pulkkinen 2017), three items served as substitutes for the original items. All five subscales-neuroticism (e.g., "I often feel tense and jittery"), extraversion (e.g., "I like to have a lot of people around me"), conscientiousness (e.g., "I'm pretty good about pacing myself so as to get things done on time"), openness (e.g., "I have a lot of intellectual curiosity"), and agreeableness (e.g., "I would rather cooperate with others than compete with them")- were assessed using 12 items, and the mean score of the items was calculated for each trait. The response scale ranged from 1 to 5 (strongly disagree to completely agree). Cronbach's alpha reliability was above 0.75 for each personality trait (Kokko et al. 2015).

To alleviate possible omitted variable bias, we controlled factors that could be linked to income and mental well-being. Categories of the control variables were included in the estimations as dummies (reference categories described in parentheses). The predetermined control variables included gender $(0=$ male $)$ and the follow-up year $2009(0=2001)$. Other controls were relationship status, state of health, and size of household. The categories for relationship status were married, lives in cohabitation without marriage, single, and divorced or widowed $(0=$ married). State of health was evaluated based on the following question: "During the past year, how would you describe your health as a whole?" The categories used were very good, fairly good, moderate, fairly bad, and very bad health $(0=$ fairly good health). Lastly, we controlled for the size of the household that the participants reported as part of the LSQ.

In the appendix, we show that our results are robust for an additional set of labor market and education controls. Specifically, we added controls for employment situation, stability of career line, occupational status, and education. Approximately $90 \%$ of workers in Finland are trade unions members. Therefore, job loss does not result in a dramatic fall in income; instead, income declines gradually with the duration of unemployment. However, losing a job might contribute to mental well-being, despite income stability, as one's daily work routine and colleagues are lost. Similarly, the stability of the career line and occupational status are likely to have separate associations with stress level and mental well-being. Therefore, it is important to show the results with these controls. Employment status was categorized as unemployed, part-time, or full-time employee $(0=$ full-time employee). The stability of the career line was based on information collected about work history and was categorized as unstable, changeable, or stable working career $(0=$ stable 
working career). Occupational status was based on a question related to one's latest professional title and was classified into upper white-collar, lower white-collar, and blue-collar occupation $(0=$ lower white-collar $)$, and education was categorized as course, vocational school, vocational college, and university degree $(0=$ vocational school). Further information about the control variables can be found in Pulkkinen and Kokko (2010).

\subsection{Data Analysis}

The statistical analyses were conducted using Stata/SE 14, employing pooled ordinary least squares (OLS; Eq. 1) and fixed effects (FE; Eqs. 2 and 3) estimations. The baseline specifications were:

$$
\begin{gathered}
\text { mwe }_{i t}=\alpha+\beta \log i_{i t}+\lambda_{\pi} P_{i t}+\gamma_{k} X_{i t}+\varepsilon_{i t} \\
m w e_{i t}=\alpha+\beta \log i_{i t}+\lambda_{\pi} P_{i t}+\gamma_{k} X_{i t}+\mu_{i}+\varepsilon_{i t} \\
m w e_{i t}=\alpha+\beta \log i_{i t}+\lambda_{\pi} P_{i t}+\gamma_{k} X_{i t}+\delta_{\rho} P_{i t} * \log i_{i t}+\mu_{i}+\varepsilon_{i t}
\end{gathered}
$$

where an individual's mental well-being $\left(\right.$ mwe $\left._{\mathrm{it}}\right)$ was regressed on income $\left(i_{i t}\right)$, personality traits $\left(P_{i t}\right)$, and observable covariates $\left(X_{i t}\right)$. In models 2 and 3, unobserved time-invariant effects $\left(\mu_{i}\right)$ were removed, and model 3 further examined whether personality traits moderated the associations between income and mental well-being, with $P_{i t} * \log i_{i t}$ capturing the interaction of each personality trait with income.

OLS and FE estimations utilize different types of variation: cross-sectional variation and within-individual variation, respectively. As we pooled the data, i.e., combined the observations from ages 42 and 50, there were two observations from each individual therein. OLS regression considers each observation separately, regardless of age. Standard errors are likely to be correlated over time at the individual level, which we corrected by clustering the standard errors at the individual level. Conversely, FE examines how the change in an individual's income associates with changes in his/her well-being between ages 42 and 50, taking the controls into account. The FE estimate gives the average of these individuallevel changes.

\section{Results}

\subsection{Data Description}

Table 1 presents the descriptive statistics for the key variables at ages 42 and 50. Mental well-being and its dimensions-emotional (and its sub-dimensions happiness and positive mood), psychological, and social well-being-gross monthly income, and agreeableness increased, whereas extraversion, neuroticism, and openness decreased significantly $(p<0.05)$ from age 42 to 50. Descriptive statistics for the control variables are presented in the appendix (Table 5). Table 2 presents the correlations in the pooled sample, i.e., including observations from ages 42 and 50. The dimensions of mental well-being (emotional, psychological, and social well-being and low depression) were strongly positively correlated (ranging from 0.28 to 0.85 ), as shown in previous JYLS analyses (Kokko et al. 2015). We found further moderately positive correlations between income and the wellbeing measures, with the coefficients ranging from 0.12 to 0.34 . The correlations were 
Table 1 Means and standard deviations of mental well-being and its dimensions, income, and personality traits $(\mathrm{N}=163) ; p$ values from paired t-tests

\begin{tabular}{|c|c|c|c|c|c|}
\hline & \multicolumn{2}{|c|}{ Age 42 (2001) } & \multicolumn{2}{|c|}{ Age 50 (2009) } & \multirow{2}{*}{$p$ value } \\
\hline & Mean & $\mathrm{SD}$ & Mean & SD & \\
\hline \multicolumn{6}{|l|}{ Well-being } \\
\hline Mental well-being (S) & -0.14 & 1.00 & 0.14 & 0.98 & .000 \\
\hline Emotional well-being (S) & -0.09 & 1.05 & 0.09 & 0.94 & .047 \\
\hline Happiness & 1.75 & 1.16 & 2.04 & 0.69 & .002 \\
\hline Life satisfaction & 3.13 & 0.35 & 3.13 & 0.36 & .998 \\
\hline Positive mood & 2.88 & 0.64 & 3.00 & 0.56 & .038 \\
\hline Negative mood (R) & 3.84 & 0.26 & 3.84 & 0.26 & .920 \\
\hline Psychological well-being & 3.17 & 0.34 & 3.22 & 0.31 & .015 \\
\hline Social well-being & 2.85 & 0.36 & 2.99 & 0.39 & .000 \\
\hline Depression (R) & 3.54 & 0.35 & 3.59 & 0.37 & .057 \\
\hline \multicolumn{6}{|l|}{ Income } \\
\hline Gross monthly income (thousands) & 2.23 & 1.06 & 2.84 & 1.34 & .000 \\
\hline Household finances & 2.77 & 0.70 & 2.87 & 0.65 & .077 \\
\hline \multicolumn{6}{|l|}{ Personality traits } \\
\hline Agreeableness & 3.65 & 0.52 & 3.73 & 0.44 & .005 \\
\hline Conscientiousness & 3.70 & 0.53 & 3.68 & 0.50 & .484 \\
\hline Extraversion & 3.31 & 0.55 & 3.23 & 0.55 & .006 \\
\hline Neuroticism & 2.34 & 0.64 & 2.24 & 0.59 & .005 \\
\hline Openness to new experiences & 3.37 & 0.58 & 3.27 & 0.54 & .001 \\
\hline
\end{tabular}

Mental and emotional well-being are sum variables constructed using standardized scores

$S$ standardized score, $R$ reversed score

Table 2 Correlations between mental well-being, its dimensions, and income variables-pooled sample $(\mathrm{N}=326)$

\begin{tabular}{|c|c|c|c|c|c|c|c|}
\hline & 1 & 2 & 3 & 4 & 5 & 6 & 7 \\
\hline 1. Mental well-being & - & & & & & & \\
\hline 2. Emotional well-being & $0.78 * *$ & - & & & & & \\
\hline 3. Psychological well-being & $0.85^{* *}$ & $0.60 * *$ & - & & & & \\
\hline 4. Social well-being & $0.72 * *$ & $0.39 * *$ & $0.54 * *$ & - & & & \\
\hline 5. Depression (R) & $0.70^{* *}$ & $0.41 * *$ & $0.44 * *$ & $0.28 * *$ & - & & \\
\hline 6. Gross monthly income & $0.34 * *$ & $0.24 * *$ & $0.25 * *$ & $0.28 * *$ & $0.30^{* *}$ & - & \\
\hline 7. Household finances & $0.24 * *$ & $0.24 * *$ & $0.19 * *$ & $0.12 *$ & $0.19 * *$ & $0.34 * *$ & - \\
\hline
\end{tabular}

$R$ reversed score

$* * p<0.01, * p<0.05$

more consistent between gross monthly income and the well-being measures (0.24-0.34) than between household finances and the well-being measures $(0.12-0.24)$. The correlation coefficient between gross monthly income and household finances was 0.34 , describing a moderate correlation. 


\subsection{Income and Mental Well-Being}

We first investigated the relationship between income and well-being using gross monthly income (Table 3, upper part). Three specifications (1,2, and 3) were separately estimated for the standardized scores for mental well-being and its dimensions: emotional, psychological, and social well-being and reversed depression. The bivariate OLS model (specification 1) indicated positive associations between income and all the well-being measures. Including the standardized scores for the personality traits and control variables (specification 2) and accounting for unobserved heterogeneity (specification 3) yielded a statistically significant coefficient for income in one case: reversed depression.

We replicated the analysis using household finances as an income variable (Table 3, lower part). In the OLS models, household finances were positively associated with mental well-being and with the dimension of emotional well-being, indicating more robust relations between income and well-being. The associations between household finances and other well-being measures were similar to those of our previous results: in the bivariate OLS models, household finances were positively associated with psychological well-being and reversed depression. ${ }^{4}$

The appendix (Table 6) reports on the relationships between income and the well-being variables when an additional set of education and labor market controls are included in the models. The results are robust for the inclusion of the additional control variables. The only difference was that the estimate of gross monthly income was no longer statistically significant in the case of reversed depression. The standard errors are similar between Tables 3 and 6, confirming that our results do not suffer from multicollinearity. All the results were further robust for the exclusion of individuals with top-coded income values. ${ }^{5}$

\subsection{The Moderating Role of Personality Traits in the Associations Between Income and Mental Well-Being}

To explore the moderating role of personality traits in the income-mental well-being associations, we augmented our FE models with income-personality trait interaction terms (Table 4), and thus utilized only the within-individual variation. The income variable interacting with the standardized scores for the personality traits is gross monthly income in specification 1, followed by household finances in specification 2. Our analyses indicated, first, that extraversion negatively moderated the monthly gross income-mental well-being relationship (specification 1), implying that a higher score in extraversion is associated with a more negative income-mental well-being relationship. Second, when the dimensions of mental well-being were separately analyzed, agreeableness and extraversion negatively moderated the association between gross monthly income and emotional wellbeing, while openness positively moderated this association (specification 1). Contrary to the negative moderators, the result for openness suggests that the higher the score in this personality trait, the more positive the association between gross monthly income and

\footnotetext{
4 The bivariate FE model (not reported) indicated a positive association between household finances and emotional well-being (point estimate 0.294, standard deviation 0.136).

5 The bivariate OLS associations between income and the well-being measures were positive and statistically significant, except for social well-being. In the multivariate OLS setting, gross monthly income was positively associated with reversed depression, and household finances were positively associated with mental well-being and, particularly, one of its dimensions, i.e., emotional well-being.
} 


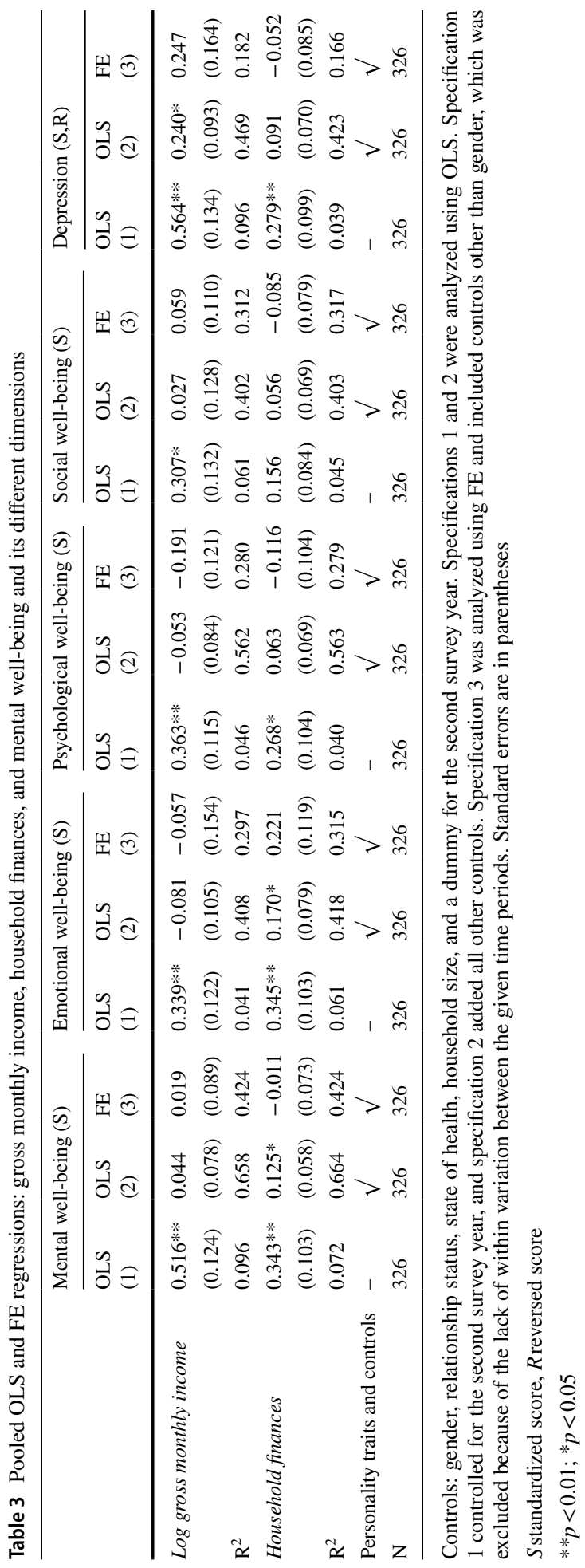




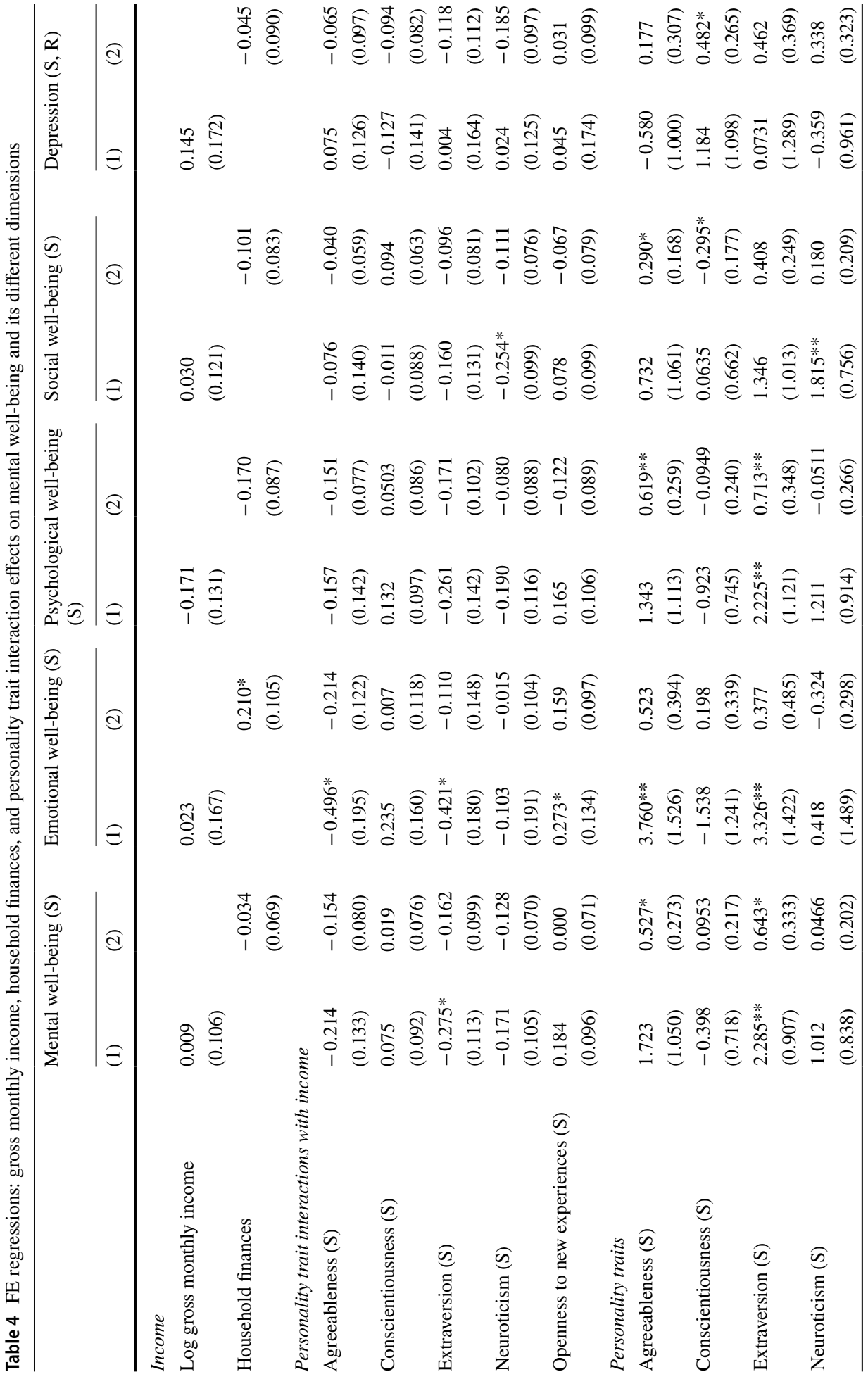




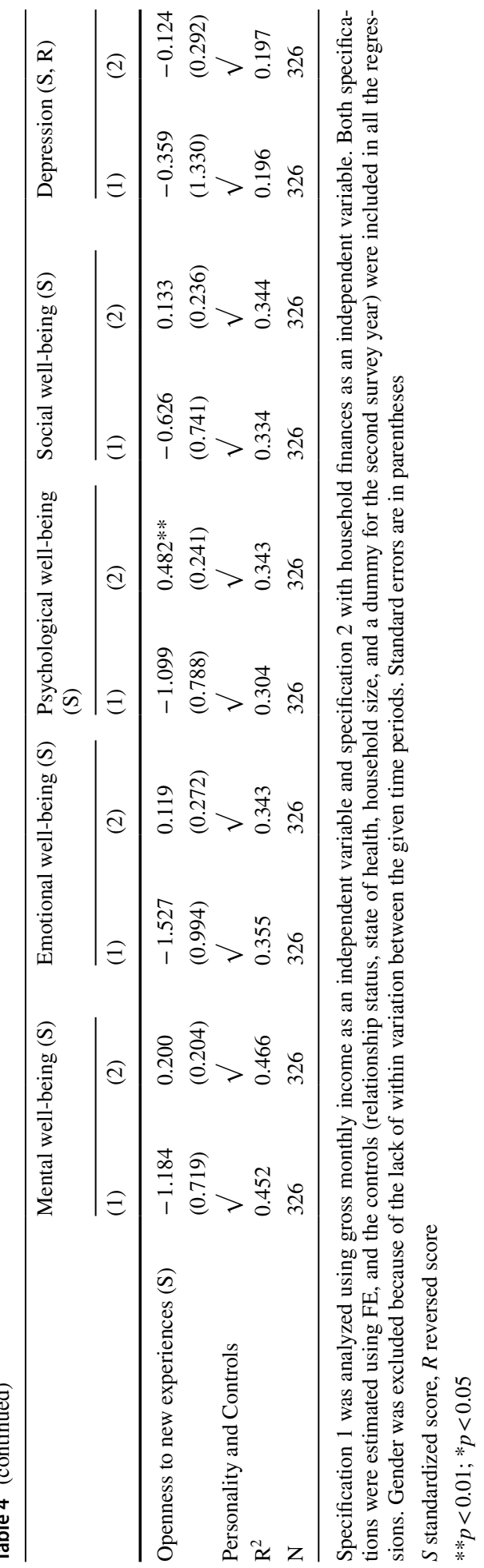



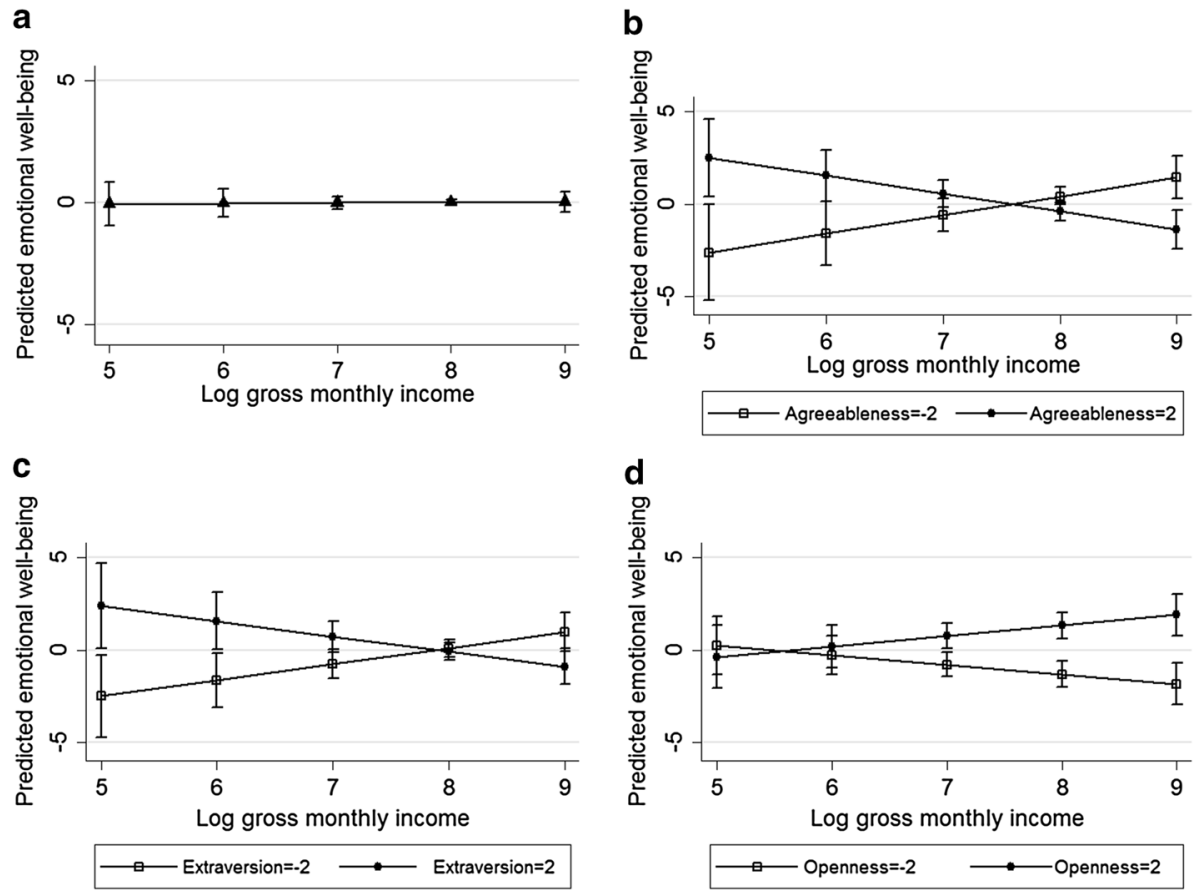

Fig. 1 Predicted emotional well-being (S) by a gross monthly income, b gross monthly income and agreeableness (S), c gross monthly income and extraversion (S): and $\mathbf{d}$ gross monthly income and openness (S). A value of -2 describes a personality trait value of two standard deviation units below the mean, and a value of 2 describes two standard deviation units above the mean. $S$ standardized

emotional well-being. Finally, neuroticism negatively moderated the association between gross monthly income and social well-being (specification 1). The inclusion of the labor market controls (Appendix, Table 7) yielded coefficients that were more often statistically significant and consistent in magnitude when compared with those presented in Table 4. The results were further robust for the exclusion of the top-coded income values. ${ }^{6}$

Figure 1 provides a graphical illustration of the results, using emotional well-being as a dependent variable (Table 4, specification 1), as the statistically significant interaction effects were mainly found for emotional well-being. Specifically, Fig. 1 graphs average emotional well-being for the different values of gross monthly income and the different values of income and agreeableness, extraversion, or openness, adjusted for the other covariates in our FE model. The predictive margins are presented with $95 \%$ confidence intervals for the means. Figure 1a shows the slightly positive relationship between gross monthly income and emotional well-being. In Fig. 1b, the association between gross monthly

\footnotetext{
${ }^{6}$ Extraversion negatively moderated the association between gross monthly income and mental well-being. Agreeableness and extraversion negatively moderated the relationship between gross monthly income and emotional well-being, while openness positively moderated this relationship. Further, extraversion negatively moderated the gross monthly income-psychological well-being association, and neuroticism negatively moderated the gross monthly income-social well-being relationship. Using household finances as an independent variable, neuroticism was found to be a negative moderator of reversed depression.
} 
income and emotional well-being is graphed for individuals with very high and very low agreeableness scores: a value of -2 describes agreeableness at two standard deviation units below the mean (marked as a hollow square), while a value of 2 describes agreeableness at two standard deviation units above the mean (marked as a circle). Figure 1b confirms the negative moderating role of agreeableness: at very high agreeableness scores (agreeableness $=2$ ), the association between income and emotional well-being seems to be negative, whereas at very low agreeableness scores (agreeableness $=-2$ ), the association appears to be positive. While individuals with high agreeableness scores start with higher emotional well-being at low income levels, those with low agreeableness surpass them at higher income levels. The difference in emotional well-being seems largest at low income levels.

Figure 1c clarifies the negative moderating role of extraversion. Compared to the income-emotional well-being association shown in Fig. 1a, individuals with very high extraversion scores (extraversion $=2$ ) demonstrate a more negative association between income and emotional well-being, while those with very low extraversion scores (extraversion $=-2$ ) show a more positive association. Figure 1d turns to openness and its moderating role in the gross monthly income-emotional well-being association. The figure illustrates that individuals with high openness scores (openness =2) seem to have a positive association between income and emotional well-being, whereas for individuals with low openness scores (openness $=-2$ ), the association is negative. Unlike for agreeableness and extraversion (Fig. 1b, c), the differences in emotional well-being seem to be greatest at high income levels in the case of openness. For example, individuals with high and low openness scores have very similar emotional well-being when gross monthly income is low, but individuals with high openness scores seem to be better off when gross monthly income is high.

\section{Discussion}

The existing economics literature has shown a positive short-term relationship between GDP or income and the dimensions of emotional well-being (typically happiness or life satisfaction; see, e.g., Boyce and Wood 2011; Deaton 2008; Stevenson and Wolfers 2008). We found income to be positively associated with the well-being measures in the bivariate OLS setting (except for the household finances-social well-being association). Further, the relationships between gross monthly income and reversed depression and between household finances and mental well-being and one of its dimensions (emotional well-being) were positive in the multivariate OLS setting. After the inclusion of the labor market and education controls, the estimate of income in the case of reversed depression was no longer statistically significant. This result suggests that households share assets and liabilities, and therefore, the financial situation of the household may be more crucial than individual income for mental well-being. A household's financial situation may be further tightly related to emotional well-being, especially because emotional well-being is composed of happiness, life satisfaction, and affectivity. One component of life satisfaction is satisfaction with one's financial situation. Therefore, an individual evaluating his/ her household financial situation as tight might also report dissatisfaction with his/her current financial situation. Further, the income variables used were moderately correlated (0.34) and describe different kinds of income. Gross monthly income illustrates the taxable income, pensions, and social benefits received by an individual, whereas household 
finances illustrate how an individual experiences his/her personal financial situation or that of the family that he/she has set up.

The majority of our income-mental well-being estimates, however, described insignificant associations between income and the mental well-being measures. This supports the existing economics literature, which has illustrated very small effect sizes (Angeles 2011), and has shown that, in the long run, the positive relationship between GDP and life satisfaction vanishes (Easterlin et al. 2010). The limited role of income in mental well-being is also supported by the psychological literature, which has illustrated that factors such as personality traits are highly important contributors to mental well-being. According to a meta-analysis by Steel, Schmidt, and Shultz (2008), personality traits explain 40-60\% of the variation in the mental well-being indices. Using the present JYLS data, it has been shown that the role of the personality traits is smallest for happiness (approximately $20 \%$; Korkalainen 2007) and smaller for life satisfaction than for psychological well-being (Kokko et al. 2013a). Interestingly, the economics literature has concentrated on happiness and life satisfaction.

Another possible explanation for these insignificant relationships is that a higher income level might be associated with financial resources being exceeded, such as high debt. Tay et al. (2017) showed that debt is linked to subjective well-being through satisfaction. This reasoning is further supported by the JYLS data: at low gross monthly income levels (from $€ 1000$ to $€ 2200$ per month), the household financial situation improved when income increased. Between $€ 2200$ and $€ 3400$ per month, the household financial situation remained stable, and from $€ 4600$ per month onwards, household finances did not improve; rather, they weakened (Pulkkinen 2017). It could also be that not only are financial resources exceeded when income increases, but higher income may relate to larger workloads, higher stress levels, or less free time, which could further translate into lower well-being.

The personality traits moderated-i.e., affected well-being reactions arising from changes in income - the relationship between income and well-being. Extraversion negatively moderated the relationships between gross monthly income and mental well-being. In addition to general mental well-being, the dimensions of emotional and social wellbeing were moderated by the personality traits. Agreeableness and extraversion negatively moderated the gross monthly income-emotional well-being association, while openness positively moderated this association. The gross monthly income-social well-being relationship was moderated by neuroticism.

The negative moderating effect of agreeableness is intuitive, as highly agreeable individuals can be characterized as compliant and altruistic (Costa and McCrae 1989). These individuals reported high scores for questions such as "I would rather cooperate with others than compete with them." Therefore, such individuals may not enjoy high income as much as less agreeable individuals. Compared to our results, the existing literature has reported insignificant and, in general, smaller coefficients regarding the moderating role of agreeableness on the income-life satisfaction association (Boyce and Wood 2011; Soto and Luhmann 2012; Proto and Rustichini 2015).

The existing literature on the moderating role of extraversion and neuroticism has mixed results. For example, for life satisfaction, Boyce and Wood (2011) reported a positive interaction effect between income and extraversion for women, but found no significant effects for men. We speculated whether highly extraverted individuals on high incomes were satisfied with their financial situation and, therefore, gained nothing from income changes. For neuroticism, Proto and Rustichini (2015) as well as Soto and Luhmann (2012), found that higher levels of life satisfaction due to income increases for individuals with high 
neuroticism scores. However, the results of Boyce and Wood (2011) showed inconsistencies between the different models used. For openness, Boyce and Wood (2011) found a negative interaction for women, whereas Soto and Luhmann (2012) reported inconsistencies between the different data sets analyzed. Proto and Rustichini (2015) illustrated that openness has no effect on how income affects life satisfaction. Our results suggest the opposite moderating effect. However, the well-being variables assessed here differed, as the emotional well-being variable used in this study consisted of several variables (i.e., life satisfaction, happiness, and affectivity) instead of only life satisfaction.

We studied each personality trait separately. However, human beings comprise a combination of several personality traits that likely operate together (Pulkkinen 2017). A possible avenue for future research would be to examine the marginal utility of income and the moderating role of personality profiles, i.e., homogenous subgroups with distinct Big Five personality traits, instead of separate personality traits. For example, Kinnunen et al. (2012; see Pulkkinen 2017 for updated titles of the profiles) illustrated the existence and continuity of the following personality profiles in the JYLS data: Resilient (high in extraversion and conscientiousness, low in neuroticism); Brittle (high in neuroticism, low in extraversion, and lower than average in openness, conscientiousness, and agreeableness); Overcontrolled (low in extraversion and openness, but differed from the Brittle in higher conscientiousness and agreeableness and lower neuroticism); Undercontrolled (high in openness and extraversion, low in conscientiousness), and Ordinary (mean value in all personality traits).

Our main aim in the present study was to explain mental well-being on the basis of income variables and how personality traits moderate the relation between income and mental well-being. However, it is also likely that high mental well-being contributes to an individual's work career and, consequently, income level. We would like to emphasize that our results do not provide evidence of a causal relation between income and mental well-being, as significant relationships were only found using OLS. Evidence of the moderating role of personality traits in the income-mental well-being associations may be interpreted as support for causal relations, as the FE estimates describe, at best, average causal effects. Further research is needed to confirm our results, as the analyses were based on a moderately-sized dataset, and the insignificant results might have been due to a lack of statistical power. It would be interesting to further examine the causal relations over a longer period. Further, an avenue for future research would be to investigate whether the moderating effect of income on mental well-being differs between positive and negative income shocks. We believe that personality traits moderate both types of income shocks, but an assessment of how the moderating effects differ between these shocks is beyond the scope of the present paper.

Finally, the data collection at age 50 was undertaken in 2009, that is, after the 2008 US financial crisis and at the time of the financial crisis in Europe. In Finland, the crisis led to an $8 \%$ decrease in GDP, a $20 \%$ decrease in exports, and a $17 \%$ decrease in private investments in 2009. However, the decrease in private consumption was small due to fiscal policy actions and low interest rates. Further, unemployment increased only by three percentage points between 2008 and 2009 and started to decrease by 2010. Overall, the labor markets survived the crisis years well (Freystätter and Mattila 2011). In our data, unemployment decreased, gross monthly income increased, and the household financial situation improved between the ages of 42 and 50. Therefore, we believe that even though the public sector suffered significantly during the crisis, and even though the accumulated budget deficit may affect the private sector for years to come, in 2009, our participants were not significantly affected by the crisis. 


\section{Conclusions}

By using an age-cohort representative sample of longitudinal data, the present study suggested a positive, though limited, relationship between income and well-being in middle age. We found positive bivariate associations between income and mental well-being and its dimensions: emotional, psychological, and social well-being and reversed depression (OLS). Following the inclusion of the personality traits and control variables, gross monthly income was statistically significantly associated with reversed depression, and experienced household finances were related to mental well-being and its emotional wellbeing dimension (OLS). Once the labor market and education controls were added, income no longer yielded a statistically significant coefficient in the case of reversed depression.

Based on our results, the marginal utility of income seemed to depend on personality traits (FE): agreeableness and extraversion negatively moderated the gross monthly income-emotional well-being relationship, while openness positively moderated this relationship. In addition to emotional well-being, extraversion negatively moderated the relationship between gross monthly income and general mental well-being, while neuroticism negatively moderated the association between gross monthly income and the dimension of social well-being. An avenue for future research would be to examine why certain personality traits moderate specific dimensions of mental well-being.

Based on our results, income, particularly the experienced household financial situation, was most consistently associated with the dimension that the economics literature has concentrated on: emotional well-being. Similarly, in the interaction analyses, the personality traits mainly moderated the income and emotional well-being relationships. While it may be interesting to see how income associates with emotional well-being or one of its subcomponents (such as happiness or life satisfaction), we suggest further research into general mental well-being in relation to income. If only one dimension of mental well-being is studied, it should be noted that it would not describe the individual's mental well-being as a whole.

Acknowledgements Open access funding provided by University of Jyväskylä (JYU). The most recent data collection in the Jyväskylä Longitudinal Study of Personality and Social Development (JYLS) in 2009 was funded through Academy of Finland: award number 118316 was granted to Kokko and 127125 to Pulkkinen. Syrén also gratefully acknowledges financial support from the OP Group Research Foundation (project numbers 201500090, 201600189 and 20170093).

\section{Compliance with Ethical Standards}

Conflict of interest Authors declare that they have no conflict of interest.

Open Access This article is distributed under the terms of the Creative Commons Attribution 4.0 International License (http://creativecommons.org/licenses/by/4.0/), which permits unrestricted use, distribution, and reproduction in any medium, provided you give appropriate credit to the original author(s) and the source, provide a link to the Creative Commons license, and indicate if changes were made.

\section{Appendix}

See Tables 5, 6 and 7. 
Table 5 Means and standard deviations of the control variables $(\mathrm{N}=163)$; $p$ values from paired t-tests

\begin{tabular}{|c|c|c|c|c|c|}
\hline & \multicolumn{2}{|c|}{ Age 42 (2001) } & \multicolumn{2}{|c|}{ Age 50 (2009) } & \multirow[t]{2}{*}{$p$ value } \\
\hline & Mean & $\mathrm{SD}$ & Mean & SD & \\
\hline \multicolumn{6}{|l|}{ Employment situation } \\
\hline Unemployed & 0.09 & 0.28 & 0.08 & 0.27 & 0.836 \\
\hline Part-time employee & 0.08 & 0.27 & 0.05 & 0.22 & 0.198 \\
\hline Full-time employee & 0.83 & 0.37 & 0.87 & 0.35 & 0.290 \\
\hline \multicolumn{6}{|l|}{ Stability of career line } \\
\hline Unstable career & 0.09 & 0.28 & 0.07 & 0.26 & 0.565 \\
\hline Changeable career & 0.08 & 0.27 & 0.09 & 0.29 & 0.696 \\
\hline Stable career & 0.83 & 0.37 & 0.83 & 0.37 & 1.000 \\
\hline \multicolumn{6}{|l|}{ Occupational status } \\
\hline Blue-collar & 0.26 & 0.44 & 0.22 & 0.42 & 0.052 \\
\hline Lower white-collar & 0.46 & 0.50 & 0.49 & 0.50 & 0.286 \\
\hline Upper white-collar & 0.28 & 0.45 & 0.29 & 0.46 & 0.319 \\
\hline \multicolumn{6}{|l|}{ State of health } \\
\hline Very good health & 0.16 & 0.37 & 0.19 & 0.39 & 0.386 \\
\hline Fairly good health & 0.64 & 0.48 & 0.53 & 0.50 & 0.029 \\
\hline Moderate health & 0.18 & 0.38 & 0.25 & 0.44 & 0.064 \\
\hline Fairly bad health & 0.03 & 0.16 & 0.03 & 0.16 & 1.000 \\
\hline Very bad health & 0.00 & 0.00 & 0.01 & 0.08 & 0.319 \\
\hline \multicolumn{6}{|l|}{ Relationship status } \\
\hline Single & 0.07 & 0.26 & 0.06 & 0.23 & 0.319 \\
\hline Married & 0.69 & 0.46 & 0.67 & 0.47 & 0.451 \\
\hline Cohabitation & 0.12 & 0.32 & 0.09 & 0.29 & 0.319 \\
\hline Divorced or widowed & 0.12 & 0.32 & 0.18 & 0.39 & 0.027 \\
\hline \multicolumn{6}{|l|}{ Size of the household } \\
\hline Household size & 3.65 & 1.34 & 3.03 & 1.26 & 0.000 \\
\hline \multicolumn{6}{|l|}{ Education } \\
\hline Course & 0.14 & 0.35 & 0.14 & 0.35 & - \\
\hline Vocational school & 0.36 & 0.48 & 0.36 & 0.48 & - \\
\hline Vocational college & 0.34 & 0.48 & 0.34 & 0.48 & - \\
\hline University & 0.15 & 0.36 & 0.15 & 0.36 & - \\
\hline \multicolumn{6}{|l|}{ Gender } \\
\hline Female & 0.55 & 0.50 & 0.55 & 0.50 & - \\
\hline \multicolumn{6}{|l|}{ Follow-up year } \\
\hline Year 2009 & 0.00 & 0.00 & 1.00 & 0.00 & - \\
\hline
\end{tabular}

Education and gender recorded no variation between ages 42 and 50 


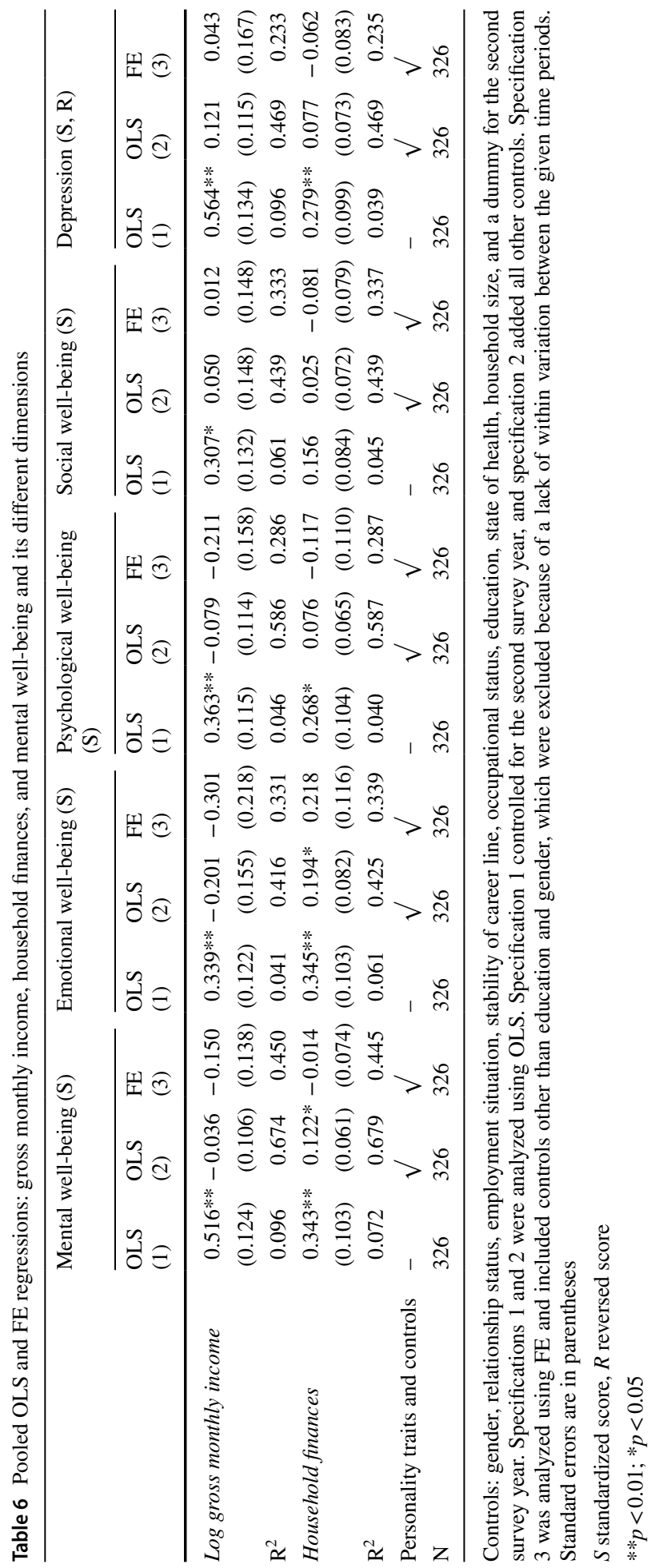




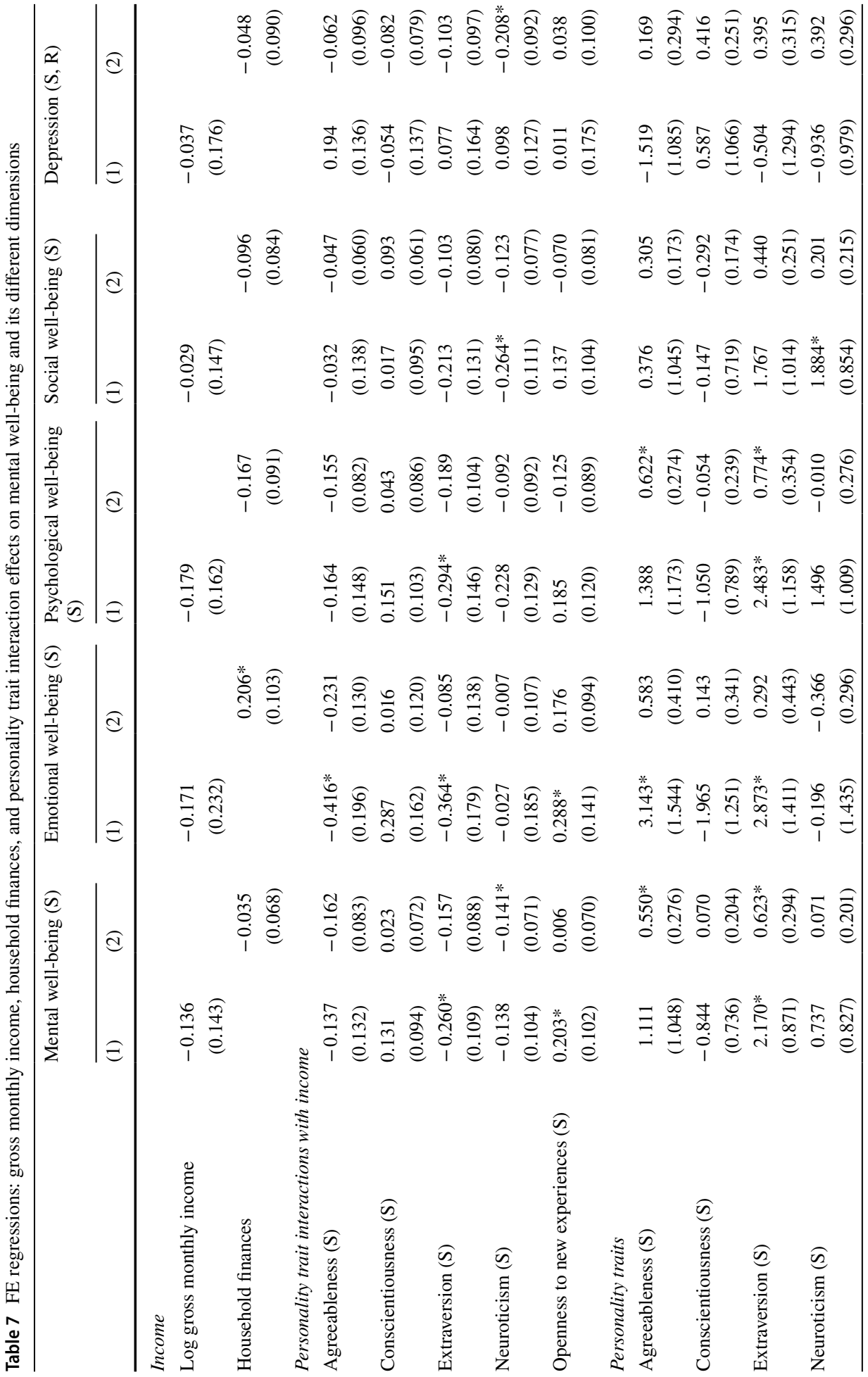




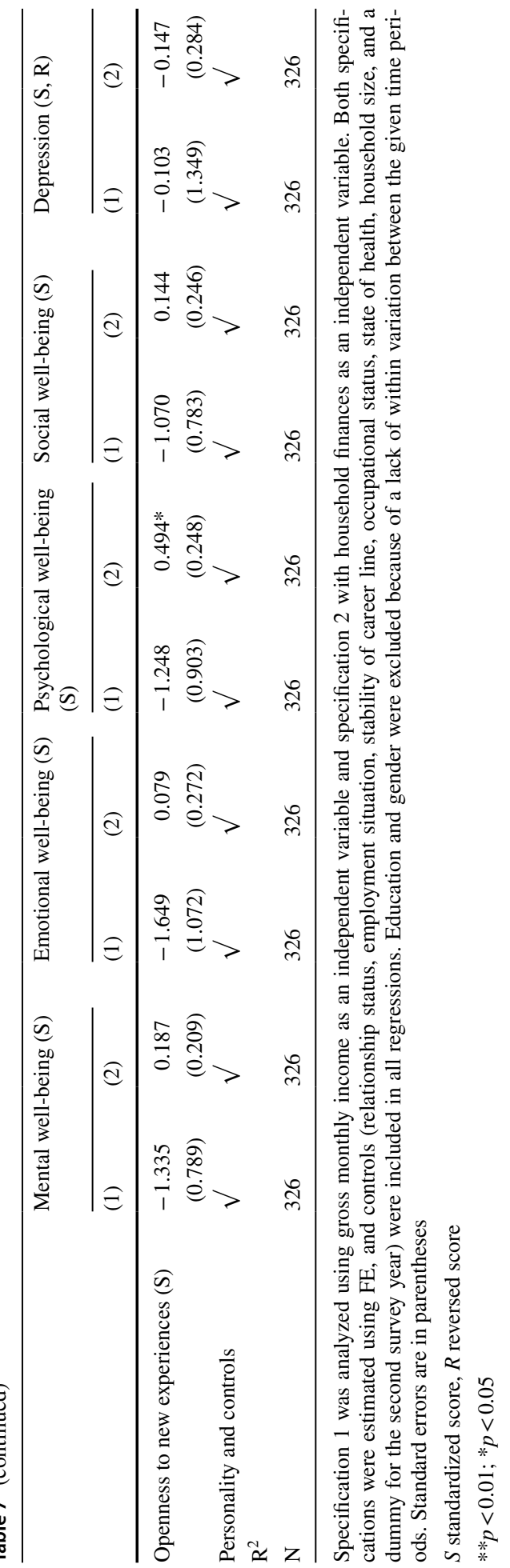




\section{References}

Angeles, L. (2011). A closer look at the Easterlin paradox. The Journal of Socio-Economics, 40(1), 67-73.

Anger, S., Camehl, G., \& Peter, F. (2017). Involuntary job loss and changes in personality traits. Journal of Economic Psychology, 60, 71-91.

Boyce, C. J., \& Wood, A. M. (2011). Personality and the marginal utility of income: Personality interacts with increases in household income to determine life satisfaction. Journal of Economic Behavior \& Organization, 78(1), 183-191.

Boyce, C. J., Wood, A., \& Powdthavee, N. (2013). Is personality fixed? Personality changes as much as "variable" economic factors and more strongly predicts changes to life satisfaction. Social Indicators Research, 111(1), 287-305.

Brown, S., \& Gray, D. (2016). Household finances and well-being in Australia: An empirical analysis of comparison effects. Journal of Economic Psychology, 53, 17-36.

Brown, S., \& Taylor, K. (2014). Household finances and the 'Big Five' personality traits. Journal of Economic Psychology, 45, 197-212.

Brown, S., Taylor, K., \& Wheatley Price, S. (2005). Debt and distress: Evaluating the psychological cost of credit. Journal of Economic Psychology, 26(5), 642-663.

Clark, A. E., Frijters, P., \& Shields, M. A. (2008). Relative income, happiness, and utility: An explanation for the Easterlin paradox and other puzzles. Journal of Economic Literature, 46(1), 95-144.

Costa, P. T., \& McCrae, R. R. (1985). The NEO personality inventory. Odessa, FL: Psychological Assessment Resources.

Costa, P., \& McCrae, R. (1989). The NEO/NEO-FFI manual supplement. Odessa, FL: Psychological Assessment Resources.

Deaton, A. (2008). Income, health, and well-being around the world: Evidence from the Gallup World Poll. The Journal of Economic Perspectives, 22(2), 53-72.

Depue, R. (1987). General behavior inventory. Ithaca, NY: Department of Psychology, Cornell University.

Diener, E. (1984). Subjective well-being. Psychological Bulletin, 95(3), 542-575.

Diener, E., Hentzelman, S. J., Kushlev, K., Tay, L., Wirtz, D., Lutes, L. D., et al. (2017). Findings all psychologists should know from the new science on subjective well-being. Canadian Psychology, 58(2), 87-104.

Diener, E., Suh, E., Lucas, R. E., \& Smith, H. L. (1999). Subjective well-being: Three decades of progress. Psychological Bulletin, 125(2), 276-302.

Drentea, P. (2000). Age, debt and anxiety. Journal of Health and Social Behavior, 41(4), 437-450.

Easterlin, R. A., McVey, L. A., Switek, M., Sawangfa, O., \& Zweig, J. S. (2010). The happiness-income paradox revisited. Proceedings of the National Academy of Sciences, 107(52), 22463-22468.

Elkins, R., Kassenboehmer, S., \& Schurer, S. (2017). The stability of personality traits in adolescence and young adulthood. Journal of Economic Psychology, 60, 37-52.

Feldman, L. A. (1995). Variations in the circumplex structure of mood. Personality and Social Psychology Bulletin, 21(8), 806-817.

Ferrer-i-Carbonell, A. (2005). Income and well-being: An empirical analysis of the comparison income effect. Journal of Public Economics, 89(5), 997-1019.

Frey, B. S. (2008). Happiness: A revolution in economics. Cambridge, MA: MIT Press.

Freystätter, H., \& Mattila, V. (2011). Finanssikriisin vaikutuksista Suomen talouteen. BoF Online, 2011(1), $1-53$.

Gallagher, M. W., Lopez, S. J., \& Preacher, K. J. (2009). The hierarchical structure of well-being. Journal of Personality, 77(4), 1025-1050.

Golsteyn, B., \& Schildberg-Hörisch, H. (2017). Challenges in research on preferences and personality traits: Measurement, stability, and inference. Journal of Economic Psychology, 60, 1-6.

Headey, B., \& Wooden, M. (2004). The effects of wealth and income on subjective well-being and ill-being. Economic Record, 80(1), 24-33.

Helson, R., Jones, C. J., \& Kwan, S. Y. (2002a). Personality change over 40 years of adulthood: Hierarchical linear modeling analyses of two longitudinal samples. Journal of Personality and Social Psychology, 83(3), 752-766.

Helson, R., Kwan, V. S. Y., John, O. P., \& Jones, C. (2002b). The growing evidence for personality change in adulthood: Findings from research with personality inventories. Journal of Research in Personality, 36(4), 287-306.

Inglehart, R., Foa, R., Peterson, C., \& Welzel, C. (2008). Development, freedom, and rising happiness: A global perspective (1981-2007). Perspectives on Psychological Science, 3(4), 264-285.

Keyes, C. L. M. (1998). Social well-being. Social Psychology Quarterly, 61(2), 121-140. 
Keyes, C. L. (2002). The mental health continuum: From languishing to flourishing in life. Journal of Health and Social Behavior, 43(2), 207-222.

Keyes, C. L. (2005). Mental illness and/or mental health? Investigating axioms of the complete state model of health. Journal of Consulting and Clinical Psychology, 73(3), 539.

Keyes, C. L. (2006). Subjective well-being in mental health and human development research worldwide: An introduction. Social Indicators Research, 77(1), 1-10.

Keyes, C. L. M., \& Waterman, M. B. (2003). Dimensions of well-being and mental health in adulthood. In M. H. Bornstein, L. Davidson, C. L. M. Keyes, K. A. Moore, \& The Center for Child Well-Being (Eds.), Well-being: Positive development across the life course (pp. 477-497). Mahwah, NJ: Lawrence Erlbaum Associates.

Kinnunen, M.-L., Metsäpelto, R. L., Feldt, T., Kokko, K., Tolvanen, A., Kinnunen, U., et al. (2012). Personality profiles and health: Longitudinal evidence among Finnish adults. Scandinavian Journal of Psychology, 53(6), 512-522.

Kokko, K., Korkalainen, A., Lyyra, A., \& Feldt, T. (2013a). Structure and continuity of well-being in mid-adulthood: A longitudinal study. Journal of Happiness Studies, 14(1), 99-114.

Kokko, K., Rantanen, J., \& Pulkkinen, L. (2015). Associations between mental well-being and personality from a life span perspective. In M. Blatný (Ed.), Personality and well-being across the life-span (pp. 134-159). London: Palgrave Macmillan.

Kokko, K., Tolvanen, A., \& Pulkkinen, L. (2013b). Associations between personality traits and psychological well-being across time in middle adulthood. Journal of Research in Personality, 47(6), $748-756$.

Kokkonen, M. (2001). Emotion regulation and physical health in adulthood: A longitudinal, personality-oriented approach. Jyväskylä: University of Jyväskylä.

Korkalainen, A. (2007). Psykologian tutkimuksessa käytettyjen hyvinvoinnin osa-alueiden suhde toisiinsa, masentuneisuuteen, persoonallisuuden piirteisiin ja objektiivisiin tekijöihin [Association between different dimensions of well-being and their links to personality traits and objective factors]. Unpublished master's thesis, University of Jyväskylä, Finland.

Lachman, M., \& Weaver, S. L. (1998). The sense of control as a moderator of social class differences in health and well-being. Journal of Personality and Social Psychology, 74(3), 763-773.

Luttmer, E. (2005). Neighbors as negatives: relative earnings and well-Being. Quarterly Journal of Economics, 120(3), 963-1002.

Mayer, J. D., \& Gaschke, Y. N. (1988). The experience and meta-experience of mood. Journal of Personality and Social Psychology, 55(1), 102.

McInerney, M., Mellor, J. M., \& Nicholas, L. H. (2013). Recession depression: Mental health effects of the 2008 stock market crash. Journal of Health Economics, 32(6), 1090-1104.

Mroczek, D. K., \& Spiro, A., III. (2003). Modeling intraindividual change in personality traits: Findings from the normative aging study. Journals of Gerontology B: Psychological Sciences and Social Sciences, 58(3), 153-165.

Mueller, G., \& Plug, E. (2006). Estimating the effect of personality on male and female earnings. Industrial and Labour Relations Review, 60(1), 3-22.

Official Statistics of Finland (OSF): Consumer price index [e-publication]. ISSN=1799-0254. Helsinki: Statistics Finland. http://www.stat.fi/til/khi/index_en.html. Accessed June 13, 2017.

Perho, H., \& Korhonen, M. (1993). Elämänvaiheiden onnellisuus ja sisältö keski-iän kynnyksellä [Happiness of life stages in front of middle age]. Gerontologia, 7(4), 271-285.

Proto, E., \& Rustichini, A. (2015). Life satisfaction, income and personality. Journal of Economic Psychology, 48, 17-32.

Pulkkinen, L. (2017). Human development from middle to childhood to middle adulthood: Growing up to the middle-aged (in collaboration with Katja Kokko). London: Routledge.

Pulkkinen, L., \& Kokko, K. (2010). Keski-ikä elämänvaiheena [Middle age as a stage of life]. Reports from the Department of Psychology, University of Jyväskylä, Jyväskylä, p. 352.

Pulkkinen, L., Kokko, K., \& Rantanen, J. (2012). Paths from socioemotional behavior in middle childhood to personality in middle adulthood. Developmental Psychology, 48(5), 1283-1291.

Pulver, A., Allik, J., Pulkkinen, L., \& Hämäläinen, M. (1995). A Big Five personality inventory in two non-Indo-European languages. European Journal of Personality, 9(2), 109-124.

Rantanen, J., Metsapelto, R.-L., Feldt, T., Pulkkinen, L., \& Kokko, K. (2007). Long-term stability in the Big Five personality traits in adulthood. Scandinavian Journal of Psychology, 48(6), 511-518.

Roberts, B. W., Caspi, A., \& Moffitt, T. (2001). The kids are alright: Growth and stability in personality development from adolescence to adulthood. Journal of Personality and Social Psychology, 81(4), $670-683$. 
Roberts, B. W., Caspi, A., \& Moffitt, T. (2003). Work experiences and personality development in young adulthood. Journal of Personality and Social Psychology, 84(3), 582-593.

Roberts, B. W., \& Mroczek, D. (2008). Personality trait change in adulthood. Current Directions in Psychological Science, 17(1), 31-35.

Roberts, B. W., Walton, K., Bogg, T., \& Caspi, A. (2006a). De-investment in work and non-normative personality trait change in young adulthood. European Journal of Personality, 20(6), 461-474.

Roberts, B. W., Walton, K., \& Viechtbauer, W. (2006b). Patterns of mean-level change in personality traits across the life course: A meta-analysis of longitudinal studies. Psychological Bulletin, 132(1), 1-25.

Robitschek, C., \& Keyes, C. L. (2009). Keyes's model of mental health with personal growth initiative as a parsimonious predictor. Journal of Counseling Psychology, 56(2), 321.

Russell, J. A., \& Carroll, J. M. (1999). On the bipolarity of positive and negative affect. Psychological Bulletin, 125(1), 3.

Ryff, C. D. (1989). Happiness is everything, or is it? Explorations on the meaning of psychological wellbeing. Journal of Personality and Social Psychology, 57(6), 1069.

Ryff, C. D., \& Keyes, C. L. M. (1995). The structure of psychological well-being revisited. Journal of Personality and Social Psychology, 69(4), 719-727.

Scollon, C. N., \& Diener, E. (2006). Love, work, and changes in extraversion and neuroticism over time. Journal of Personality and Social Psychology, 91, 1152-1165.

Sen, A. (1973). Behaviour and the concept of preference. Economica, 40(159), 241-259.

Sen, A. (1999). Development as freedom. New York: Random House.

Small, B. J., Hertzog, C., Hultsch, D. F., \& Dixon, R. A. (2003). Stability and change in adult personality over 6 years: Findings from the Victoria Longitudinal Study. Journals of Gerontology B: Psychological Sciences \& Social Sciences, 58(3), 166-176.

Soto, C. J., \& Luhmann, M. (2012). Who can buy happiness? Personality traits moderate the effects of stable income differences and income fluctuations on life satisfaction. Social Psychological and Personality Science, 4(1), 46-53.

Steel, P., Schmidt, J., \& Shultz, J. (2008). Refining the relationship between personality and subjective wellbeing. Psychological Bulletin, 134, 138-161.

Stevenson, B., \& Wolfers, J. (2008). Economic growth and subjective well-being: Reassessing the Easterlin paradox. Brookings Papers on Economic Activity, 39(1), 1-87.

Tay, L., Batz, C., Parrigon, S., \& Kuykendall, L. (2017). Debt and subjective well-being: The other side of the income-happiness coin. Journal of Happiness Studies, 18(3), 903-937.

Veenhoven, R. (1991). Questions on happiness: Classical topic, modern answers, blind spots. In M. Argyle, N. Schwarz, \& F. Strack (Eds.), Subjective well-being: An interdisciplinary perspective (pp. 7-26). Oxford: Pergamon.

Viinikainen, J., Kokko, K., Pulkkinen, L., \& Pehkonen, J. (2010). Personality and labour market income: Evidence from longitudinal data. Labour, 24(2), 201-220.

Waterman, A. S. (1993). Two conceptions of happiness: Contrasts of personal expressiveness (eudaimonia) and hedonic enjoyment. Journal of Personality and Social Psychology, 64(4), 678.

Zimmerman, F., \& Katon, W. (2005). Socioeconomic status, depression disparities, and financial strain: What lies behind the income-depression relationship? Health Economics, 14(12), 1197-1215.

Publisher's Note Springer Nature remains neutral with regard to jurisdictional claims in published maps and institutional affiliations. 